\title{
Consumption pattern of iodised salt in households and serum TSH levels among 5-9 year old children in the plantation sector of Sri Lanka
}

\author{
V Abeysuriya $^{1}$, A R Wickremasinghe ${ }^{1}$, P J Perera $^{2}$, A Kasturiratne ${ }^{1}$ \\ (Index words: iodine deficiency, goitre, thyroid disorders, urine iodine)
}

\begin{abstract}
Introduction Salt is the main source of iodine in areas with high rainfall and iodine deficiency is the main cause of preventable hypothyroidism. Iodisation of salt increases iodine intake, but will depend on how salt is handled. This study was carried out to assess the pattern of salt consumption in the estate population and to ascertain the relationship between household salt iodine concentration and TSH levels in children.
\end{abstract}

Methods A descriptive cross sectional study was carried out in 20 randomly selected estates in the Ratnapura district of Sri Lanka, from August to November 2009. 1683 households with at least one child between 5-9 years were surveyed to determine patterns of salt usage. A salt sample from each household was tested for adequacy of iodine (concentration $\geq 30 \mathrm{ppm}$ ). In phase two, 519 children were randomly selected from these households and serum TSH levels were assayed.

Results Salt powder (54.5\%) was preferred to salt crystals. Salt crystals were washed before use in $20 \%$ households. Salt was kept away from the fire-place in
$90.4 \%$ of households. Salt samples of $88.7 \%$ households had an adequate iodine concentration. Salt iodine concentration was significantly lower when salt was stored near a fire-place and washed before use $(p<0.001)$. The median TSH level of children from households with adequate salt iodine concentrations was significantly lower than that of children from households with inadequate salt iodine concentration $(p<0.001)$.

Conclusions A significant number of households did not have adequate iodine in salt samples probably due to inappropriate handling and storage. Consumption of salt low in iodine is associated with high serum TSH levels.

Ceylon Medical Journal 2012; 57: 69-74

\section{Introduction}

Iodine deficiency leading to hypothyroidism is the most important cause of preventable brain damage and mental retardation. The clinical and sub-clinical manifestations of iodine deficiency are collectively

Departments of ${ }^{1}$ Public Health and ${ }^{2}$ Paediatrics, Faculty of Medicine, University of Kelaniya, Sri Lanka.

Correspondence: PJP, e-mail: <priyanthaprr@gmail.com>. Received 25 October 2011 and revised version accepted 9 February 2012. Competing interests: none declared. 
identified as iodine deficiency disorders (IDD) and affect all stages of human growth and development $[1,2,3]$. To ensure elimination of iodine deficiency disorders, the national iodine deficiency disorder control programme was launched in 1992, with the aim of universal salt iodisation (USI) to ensure adequate iodine consumption by every individual [1]. There has been a significant reduction in iodine deficiency disorders (IDD) through the iodisation of salt programme. In hundred and nine countries out of the 130 countries affected by IDD, national legislation on salt iodisation is in place or in draft form. It is estimated that about $68 \%$ of households worldwide have access to iodised salt at present [4]. However, sustainability of the iodisation of salt programme has become a major issue for many countries with IDD [5].

The main sources of iodine for humans are seafood and drinking water. Geographical areas with very high rainfall have low iodine levels in soil due to washing off, thus resulting in low levels of iodine in drinking water. If an adequate amount of seafood is not consumed, people living in these areas run the risk of developing IDD. Though iodisation of salt increases the daily intake of iodine significantly, improper storage and usage may restrict the achievement of this goal [6].

Chronic iodine deficiency alters thyroid gland function, resulting in low circulating thyroxine concentrations, which increases secretion of thyrotrophin stimulating hormone (TSH) from the pituitary gland. Persistent stimulation of the thyroid gland by TSH results in goitre [7]. In children affected by IDD, the provision of iodised salt could reverse most of the clinical features, but increased thyroid volume may persist even after correction of iodine deficiency [8]. If there is a reduction of iodine intake, IDD will recur. Children are particularly vulnerable as they have lower stores of iodine and higher rates of iodine turnover than adults [7].

Since 1947, there have been many studies carried out on goitre prevalence in Sri Lanka [9]. The first systematic assessment of IDD in Sri Lanka was conducted in 1986 which revealed a goitre prevalence of $18.2 \%$ [10]. After ten years of the iodisation programme, the goitre prevalence in Sri Lanka decreased to 3.8\% in 2005 [11].

This study was carried out to describe the pattern of iodised salt consumption among estate communities and to assess the relationship between household iodine concentration and TSH levels in children.

\section{Methods}

The study was carried out in two phases. In phase one, 20 estates in the Ratnapura district were randomly selected from a list of all estates $(n=51)$ managed by Regional Plantation Companies using computer generated random numbers. Permission was obtained from the regional plantation companies and estate management to conduct the study. A pre-tested interviewer administered questionnaire was prepared in Sinhala and then translated in to Tamil. A list of households of the selected estates, in which children between 5 to 9 years were resident was obtained from the plantation welfare office. There were 2,100 households with at least one child in the 5-9 age group. Of that, 1683 households were selected randomly using computer generated random numbers. If a household had more than one child in the 5-9 year age group, only one child was recruited into the study randomly using computer generated random numbers. From each estate, 2 volunteers were selected and were given a training on data collection using the pre-tested questionnaire and the use of rapid test kits for estimation of iodine concentrations in household salt samples. The expiry date of the pack and whether the salt packs were labeled clearly by the manufacturer (i.e., whether the salt is iodised by $\mathrm{KIO}_{3}$ and having a $\mathrm{KIO}_{3}$ concentration of $30 \mathrm{ppm}$ ) and the brand name were checked prior to the test. At each house, a sample of salt ( $1 / 2$ tea spoon) was tested, using the rapidtest kit by adding two to three drops of test liquid to the sample of salt [12]. A change in colour of the salt sample to purple indicates an iodine content of $30 \mathrm{ppm}$ or more, which is the recommended concentration of iodine to be in salt.

During phase two, 519 children 5-9 years of age, living in the same households were selected using computer generated random numbers. An awareness programme was conducted by the principal investigator for heath staff involved regarding the objectives and relevance of the study before the commencement of the study. The parents were advised to bring their children to the estate dispensary on a given date. Informed written consent from the parents and/or guardians was obtained to collect a blood sample from the selected children. A medical doctor and two phlebotomists, who were well experienced and qualified, collected blood samples from children. From each child, $3 \mathrm{ml}$ of venous blood was drawn into vacutainers (BD Vacutainer SSTtm II Advance), in which serum automatically gets separated. The blood samples were kept at $4^{\circ} \mathrm{C}$ during transport to the laboratory. TSH levels were assayed using the Immulite 3 rd generation $\mathrm{TSH}$ Chemiluminescent Immunometric assay method (IMMULITE: Third Generation TSH; Siemens Medical Solutions.5210 Pasific Concours Drive, Los Angeles,CA 90045-6900,USA) [13].

Data analysis was done using SPSS version 13 software. Frequency distributions were used to describe the data. Chi-square tests and the median test were used to compare different groups.

Approval for the study was obtained from the Ethics Committee of the Faculty of Medicine, University of Kelaniya, Sri Lanka. Permission to conduct the study was obtained from the regional plantation companies and relevant managers of selected estates. Informed written consent from parents and assent from children were obtained prior to testing. 


\section{Results}

Table 1 shows where people purchase salt, and how they store and use salt. The retail shop $(36.4 \%$ of households) was the commonest source of household salt. The use of powdered salt $(54.5 \%)$ was preferred to salt crystals (44.5\%). $80 \%$ of households did not wash salt crystals before use. $9.6 \%$ of households kept salt near a fire place. Salt was most often stored in glass bottles (19.3\% in brown coloured bottles and 38.8\% in clear bottles). $88.7 \%$ of household salt samples had adequate concentrations of iodine (iodine $>30 \mathrm{ppm}$ ).

Table 2 shows the association between salt iodine concentration and use and storage practices of salt. Five brands of household salt samples were commonly used. Brands 4 and 5 were the most commonly used and brand
2 the least. There was no significant difference in the iodine concentrations of salt samples between the different brands. There was a significant reduction in salt iodine concentrations when salt was stored close to the fireplace and when crystals were washed before use $(p<0.001$ for both). The type of the container used for storing of salt, place of salt purchase and the nature of salt (crystals or powder) consumed were not associated with salt iodine concentrations.

The median TSH concentrations of children from households who consume adequately iodised salt [median $3.20 \mu \mathrm{IU} / \mathrm{ml}$; interquartile range $=2.59-3.92 \mu \mathrm{IU} / \mathrm{ml}]$ was significantly lower than that of children who do not consume adequately iodised salt (median $1.63 \mu \mathrm{IU} / \mathrm{ml}$, interquartile range $=1.10-2.20 \mu \mathrm{IU} / \mathrm{ml})\left[\right.$ Median Test $\chi^{2}=$ $78.47, p<0.001]$.

Table 1. Characteristics of household salt usage

\begin{tabular}{|c|c|c|}
\hline Variable & Number & $\%$ \\
\hline \multicolumn{3}{|c|}{ Place of obtaining household salt products ( $\mathrm{n}=1683$ ) } \\
\hline Estate co-operative shop & 224 & 13.3 \\
\hline Retail shop in the estate & 583 & 34.6 \\
\hline Shops in village & 410 & 24.4 \\
\hline Shops in town & 466 & 27.7 \\
\hline \multicolumn{3}{|l|}{ Type of salt used ( $\mathrm{n}=1683$ ) } \\
\hline Salt powder & 917 & 54.5 \\
\hline Salt crystals & 766 & 45.5 \\
\hline \multicolumn{3}{|c|}{ Washing of salt crystals before use $(\mathrm{n}=766$ ) } \\
\hline no & 613 & 80.0 \\
\hline yes & 153 & 20.0 \\
\hline \multicolumn{3}{|c|}{ Keep salt containers near fire place $(n=1683)$} \\
\hline no & 1521 & 90.4 \\
\hline yes & 162 & 9.6 \\
\hline \multicolumn{3}{|c|}{ Type of containers used for storage of salt $(\mathrm{n}=1683)$} \\
\hline Glass bottles (brown) & 325 & 19.3 \\
\hline Glass bottles (clear) & 653 & 38.8 \\
\hline Coconut shells & 361 & 21.4 \\
\hline Plastic container & 344 & 20.4 \\
\hline \multicolumn{3}{|l|}{ Household salt iodine level } \\
\hline Adequate (iodine level $\geq 30 \mathrm{ppm}$ ) & 1492 & 88.7 \\
\hline Inadequate (iodine level <30ppm) & 191 & 11.3 \\
\hline
\end{tabular}


Table 2. Association between practices of salt iodine concentration and use and storage practices of salt

\begin{tabular}{|c|c|c|c|}
\hline Variable & $\begin{array}{c}\text { Salt iodine concentration } \\
\geq 30 \mathrm{ppm} \\
\text { number }(\%)\end{array}$ & $\begin{array}{c}\text { Salt iodine concentration } \\
<30 \mathrm{ppm} \\
\text { number }(\%)\end{array}$ & Significance \\
\hline \multicolumn{4}{|l|}{ Place of purchase } \\
\hline Estate retail shop & $509(87.3)$ & $74(12.7)$ & \\
\hline Estate co-op shop & $203(90.6)$ & $21(9.4)$ & $\chi^{2}=3.65$ \\
\hline Outlet in village & $371(90.5)$ & $39(9.5)$ & $p=0.300$ \\
\hline Outlet in town & $409(87.8)$ & $57(12.2)$ & \\
\hline \multicolumn{4}{|l|}{ Type of salt used } \\
\hline Salt powder & $810(88.3)$ & $107(11.7)$ & Fisher's exact test: \\
\hline Salt crystals & $682(89)$ & $84(11)$ & $p=0.700$ \\
\hline \multicolumn{4}{|l|}{ Storage container } \\
\hline Brown glass & $286(88)$ & $39(12)$ & \\
\hline Clear glass & $585(89.6)$ & $68(10.4)$ & $\chi^{2}=13.65$ \\
\hline Coconut shell & $333(92.2)$ & $28(7.8)$ & $p=0.003$ \\
\hline Plastic container & $288(83.7)$ & $56(16.3)$ & \\
\hline \multicolumn{4}{|l|}{ Place of storage } \\
\hline Near fire & $74(45.7)$ & $88(54.3)$ & $\chi^{2}=324.3$ \\
\hline Away from fire & $1418(93.2)$ & $103(6.8)$ & $p<0.001$ \\
\hline \multicolumn{4}{|l|}{ Practice before use } \\
\hline Not washing & $583(95.1)$ & $30(4.9)$ & $\chi^{2}=115.89$ \\
\hline Washing & $99(64.7)$ & $54(35.3)$ & $p<0.001$ \\
\hline \multicolumn{4}{|l|}{ Type of salt brand } \\
\hline Brand 01 & $283(16.8)$ & $38(2.3)$ & \\
\hline Brand 02 & $105(6.2)$ & $14(0.8)$ & \\
\hline Brand 03 & $292(17.4)$ & $32(1.8)$ & $\chi^{2}=1.236$ \\
\hline Brand 04 & $402(23.9)$ & $54(3.2)$ & $p=0.872$ \\
\hline Brand 05 & $409(24.3)$ & $54(3.2)$ & \\
\hline
\end{tabular}

\section{Discussion}

The majority of households preferred to use salt powder $(54.5 \%) .20 \%$ of households washed salt crystals before use and $9.6 \%$ of households stored salt near a fireplace. $88.7 \%$ of salt samples had an adequate iodine concentration. Salt iodine concentration was significantly lower when salt was stored near a fire-place and when salt crystals washed before use $(p<0.001)$. The median TSH level of children from households consuming salt with adequate iodine was significantly lower than that of children from households consuming salt with inadequate iodine $(p<0.001)$.

Iodisation of salt remains the most effective and economical way of supplementing iodine for populations with a potential risk of having iodine deficiency. The production cost of iodised salt is approximately SL Rs. 7 per $\mathrm{kg}$ and the estimated per capita consumption of salt by an average Sri Lankan is estimated to be about $15 \mathrm{~g}$ per day $[14,15]$. Presently in Sri Lanka, it is prohibited by the law to sell salt that is not iodised. 
About $11 \%$ of the households included in this study did not have salt with an adequate concentration of iodine. As iodine concentrations did not vary by place of purchase, the most likely explanation is that the iodine content in salt was lost due to inappropriate handling during storage and usage. Two such practices identified in this study are keeping salt containers near a fire place and washing salt crystals before use. Instructions on storage and use are given in most of the salt packages and the public are educated during health education programmes regarding this. However, the results of this study emphasise the importance of reinforcing these activities.

Rapid-testing kits to determine iodine content in salt has a sensitivities of $93.3 \%$ and $93.9 \%$, and specificities of $90.4 \%$ and $40.4 \%$ for a single and multiple observers, respectively [16]. In this study we used a rapid test kit that detect an iodine concentration of $>30 \mathrm{ppm}$ in salt. There are rapid test kits which can detect salt iodine concentrations less than $30 \mathrm{ppm}$. Other Asian countries such as Indonesia, Nepal and India have used rapid test kits that can detect iodine in concentrations of more than $30 \mathrm{ppm}$ in several studies [18].

WHO guidelines specify that the iodine concentration of salt at the point of production should be 20-40 ppm (i.e., 20-40 mg per kg of salt). When the quality of iodised salt is poor, the salt is incorrectly packaged, or the salt deteriorates due to long term exposure to excessive moisture, heat, and contaminants mainly in tropical and subtropical countries, iodine losses from point of production to consumption can be well in excess of $50 \%$ [4]. Typically, an iodisation programme is considered to have achieved its objective if over $90 \%$ of households consume salt having an iodine concentration $>30 \mathrm{ppm}$ [18].

When there is iodine deficiency, thyroxine production from the thyroid gland is reduced resulting in hypothyroidism. This will result in an increased production of TSH from the anterior pituitary. Though there are many ways of diagnosing hypothyroidism, a raised serum TSH level is the best diagnostic test for this purpose. The median serum TSH level of children living in households that had low iodine levels in salt samples was significantly higher than that of children living in households with adequate iodine level in salt samples. Further, the median serum TSH level in children living in households with low iodine concentrations was closer to upper limit of normal (5.40 $\mu \mathrm{IU} / \mathrm{ml})$ [13]. This finding suggests that children consuming salt with low iodine levels are at an increased risk of developing hypothyroidism due to iodine deficiency.

Consumption of iodised salt is important in childhood as children have lower stores of iodine and higher rates of iodine turnover than do adults. This study highlights the importance that simply iodising salt will not be sufficient, but continuous education of the general public regarding proper usage of iodised salt is also essential in the prevention of IDDs.
In conclusion although iodisation of salt is compulsory by law in Sri Lanka and appears to be well regulated, a significant number of households do not have adequate levels of iodine in salt they use probably due to improper usage patterns that deplete the iodine content of salt. This study also reveals that consumption of salt that is low in iodine increases the risk of developing hypothyroidism especially in children. More targeted education and interventions are required to ensure an adequately iodised salt consumption.

\section{References}

1. Pandav CS, Moorthy D, Sankar R, Anand K, Karmarkar MG. National health programme series; National Iodine Deficiency Disorders Control Programme. National Institute of Health and Family Welfare. New Delhi. 2003; 5: 3-6, 237, 74-6.

2. Hetzel BS. The Nature and Magnitude of the Iodine Deficiency Disorders. 2nd ed. New Delhi: Oxford University Press 1997; 9-10.

3. Hetzel BS. Towards the Global Elimination of Brain Damage Due To Iodine Deficiency: The Nature and Magnitude of the Iodine Deficiency Disorders. New Delhi. Oxford University Press 2004; 3-10.

4. WHO/UNICEF/ICCIDD. Assessment of iodine deficiency disorders and monitoring their elimination. Geneva: $\mathrm{WHO} /$ NHD/ 2001.

5. Hetzel BS. Eliminating iodine deficiency disorders-the role of the International Council in the global partnership. Bulletin of the World Health Organization 2002; 80: 410-3.

6. National Council of Control of Iodine Deficiency Disorders. IDD Newsletter, 2004; 20: 1-5.

7. Delange F. Iodine deficiency. In: Braverman LE, Utiger RD, eds. Werner \& Ingbar's the thyroid: a fundamental and clinical text. 8th ed. Philadelphia: Lippincott Williams \& Wilkins, 2000: 295-316.

8. Aghini-Lombardi F, Antonangeli L, Pinchera A, et al. Effect of iodized salt on thyroid volume of children living in an area previously characterized by moderate iodine deficiency. Journal of Clinical Endocrinology and Metabolism 1997; 82: 1136-9.

9. Wilsion DC. Goiter in Ceylon and Nigeria. British Journal of Nutrition 1954; 8: 90-9.

10. Fernando MA, Balasuriya S, Herath KB, Katugampola S. Endemic goiter in Sri Lanka. Asia-Pacific Journal of Public Health 1989; 3: 11-9.

11. Jayatissa R. Prevalence of goiter by provinces. Iodine Nutritional Status in Sri Lanka. Medical Research Institute. Department of Health Care and Nutrition. 2006: 23-25.

12. Jayatissa R, Gunathillaka MM, Fernando DN. Iodine nutrition status among school children after salt iodization. Ceylon Medical Journal 2005; 50: 145.

13. IMMULITE: Third Generation TSH; Siemens Medical Solutions.5210 Pacific Concourse Drive, Los Angeles, CA 90045-6900,USA 2006. 


\section{Papers}

14. World Health Organization 1994, Iodine and health eliminating iodine deficiency disorders safely through salt iodization, Geneva. WHO/NUT/94.4.

15. Jayatissa R. Prevalence of goiter by provinces. Iodine Nutritional Status in Sri Lanka. Medical Research Institute. Department of Health care and Nutrition. 2006: 29-31.

16. Pandav CS, Arora NK, Rajan S. Validation of spot-testing kits to determine iodine content in salt. Bulletin of the World Health Organization, 2000.

17. Semba RD, de Pee S, Hess SY, et al. Child malnutrition and mortality among families not utilizing adequately iodized salt in Indonesia. American Journal of Clinical Nutrition 2008; 87: 2 438-44.

18. Indicators for assessing iodine deficiency disorders and their control through salt iodization, Geneva .WHO/NUT/94.6. 